\title{
MILAGRO: AMOR Y COMPRENSIÓN. UN ANÁLISIS FILOSÓFICO- FEMINISTA FRENTE AL MAL RADICAL DEL SIGLO XXI
}

\author{
Miracle: Love and Comprehension. A Feminist-philosophical Analysis in the Face of \\ Radical Evil of the XXI century
}

Rubí de María Gómez Campos, Universidad Michoacana de San Nicolás de Hidalgo, México Correo electrónico: rgcampos_61@yahoo.com.mx

Recepción: 18/08/2019

Aceptación: 15/01/2020

Resumen. En este trabajo comparamos el totalitarismo, definido por Arendt como la negación de toda posibilidad de convivencia humana y con ello de la política, con las sociedades violentas del presente, especialmente la situación de violencia contra las mujeres (el mal radical de nuestro tiempo). La ausencia de sentido común particularmente marcada entre hombres y mujeres - polariza a la sociedad contemporánea, en tanto produce la paradoja de presentar a la prostitución, el acoso sexual, la violación y nuevas formas de relaciones afectivas que dan continuidad a formas de imposición masculina, como ejercicios de autonomía. Las potentes nociones de la comprensión, donde se distingue el perdón de la reconciliación; el juicio que vincula la reflexión con la acción; y el milagro que posibilita pensar sin parámetros conocidos, permiten enfrentar la polarización y superar las condiciones desde las cuales debemos comprender nuestra realidad.

Palabras clave: prostitución, acoso, comprensión, juicio, milagro.

\begin{abstract}
In this essay we make a comparison of Totalitarianism, as defined by Arendt as the negation of any possibility of human coexistence and therefore of politics itself, with the violent societies of the present, specially the situation of violence against women (the radical evil of our time). The absence of common sense — particularly pronounced between men and women - polarizes contemporary society, insofar as it produces the paradox of presenting prostitution, sexual harassment, rape, and new forms of affective relationships that continue forms of masculine imposition, as exercises of autonomy. The potent notions of comprehension, where it is distinguished pardon from reconciliation; the judgment that connects reflection and action; the miracle that makes possible thought without known parameters, allow to face the polarization and to overcome the conditions from which we must comprehend our reality.
\end{abstract}

Keywords: prostitution, harassment, comprehension, judgment, miracle. 


\section{La moralidad no es el privilegio de ningún hombre en especial [...], todos pueden conquistarla. \\ Simone De Beauvoir, El existencialismo y la sabiduría de los pueblos}

En 1955, Hannah Arendt (1906-1975) dictó un curso sobre historia de la teoría política, en la Universidad de Berkeley. En su conclusión plantea una diferencia entre las posibilidades de transformación de la realidad que la política representa y el riesgo de asimilación y contribución al mal radical para quienes no son capaces de mantenerse a resguardo. Siguiendo la metáfora del título de su publicación: "Del desierto y los oasis", describe dos formas de realidad: la primera, vinculada a los procesos de decadencia social y violencia que circunda nuestro entorno contemporáneo; la segunda, como la posibilidad de superación y transformación efectiva de dichos entornos.

Arendt advierte en el texto del peligro que representan las "tormentas de arena", a las que entiende como la posibilidad de emergencia inesperada del mal totalitario. ${ }^{1} \mathrm{Al}$ oasis corresponde, por el contrario, representar el suelo del que surge la posibilidad de innovación de la que los seres humanos siempre pueden echar mano. El oasis representa la fuente de posibilidad de vida política, el sentido profundo de lo humano en su singularidad y la posibilidad de inicio para los que vendrán.

Los oasis constituyen todos esos dominios de la vida que existen independientemente, o al menos en gran medida independientemente, de las circunstancias políticas. Lo que en ellos disuena es la política, es decir, nuestra experiencia plural, pero no lo que podemos hacer y crear en la medida en que existimos en singular: en el aislamiento del artista, en la soledad del filósofo, en la relación inherentemente amundana entre seres humanos tal como existe en el amor y a veces en la amistad 'cuando un corazón se dirige directamente a otro, como en la amistad, o cuando el entre, el mundo, asciende en llamas como en el amor'. ${ }^{2}$

En este trabajo proponemos adaptar la metáfora del desierto y los oasis a una interpretación de las condiciones actuales de la vida en común. Nos autorizan las palabras

\footnotetext{
${ }^{1} \mathrm{Su}$ característica principal "reside en que se ajustan extraordinariamente bien a las condiciones del desierto. De hecho [los fenómenos totalitarios], no cuentan con nada más, y por ello parecen ser la forma política más adecuada a la vida del desierto". Hannah Arendt, "Del desierto y los oasis", La nación, 19 de noviembre, 2006, https://www.lanacion.com.ar/cultura/del-desierto-y-los-oasis-nid859761.

${ }^{2}$ Ibidem.
} 


\section{enn-claves}

de Arendt acerca de la extinción de la política: "el crecimiento moderno de la amundanidad, el declive de todo entre humano, también se puede describir como la propagación del desierto". 3 Nuestro esfuerzo consiste en aplicar algunas ideas de tres filósofas contemporáneas — Hannah Arendt, Simone de Beauvoir (1908-1986) y Simone Weil (1909-1943) — al análisis de las condiciones actuales de la vida en común, especialmente frente a la proliferación de la violencia sexual y de género contra las mujeres; violencia que se presenta como el mal radical del siglo XXI. Consideramos que la violencia machista y la ideología sexista son, en principio, efectos residuales del fenómeno totalitario cuya base (la pérdida de sentido común) se extiende hasta nuestros días, reforzando el desierto del sinsentido que representa la violencia y la desigualdad.

Nos referimos especialmente al debate actual acerca del acoso sexual, que divide la interpretación de los llamados piropos como deseables o como indeseables, y que situamos en analogía con la pérdida del sentido común (pulverización de los criterios para juzgar y distinguir el mal del bien) que caracteriza, según Arendt, una causa profunda del fenómeno totalitario. Nuestro propósito no es deconstruir las producciones teóricas de los filósofos quienes en su mayoría mantienen distancia de los planteamientos de justicia que sostiene la teoría feminista - sino atender al pensamiento de mujeres filósofas ${ }^{4}$ para indagar, desde el marco teórico de filosofía feminista, la posibilidad de desarrollar conceptos que permitan comprender más profundamente, y sin omitir el hecho de la diferencia de los sexos, nuestra compleja realidad social y cultural.

Algunas filósofas, como Hannah Arendt, rechazaron la posibilidad de pensar desde su condición de mujer y no se concibieron como feministas; sin embargo, casi todas las grandes pensadoras del siglo XX (feministas o no) despliegan portentosas propuestas de filosofía política que se distancia del modelo masculino generalizado de hacer filosofía por el énfasis prestado a la experiencia. ${ }^{5}$ Una de las nociones más importantes de la filosofía

\footnotetext{
3 Ibidem. El editor acota la definición de "amundanidad" como "imposibilidad de una comunión de los hombres con el cosmos y entre sí", y el "entre humano" como la "distancia que separa pero al mismo tiempo posibilita el encuentro".

${ }^{4}$ Según Arendt, la posibilidad del ejercicio de la violencia ancla en casi cualquier forma de relación social; para Simone Weil la injusticia de la opresión social es parte de toda forma de producción económica en cualquier cultura, y para Simone de Beauvoir la desigualdad es constitutiva de la vida humana.

5 "La mujer capta mucho más la realidad; cuando él ha ordenado todas las cifras, o convertido las latas de sardinas en monedas,sólo ha captado cosas abstractas [...] La famosa 'sensibilidad femenina' participa un poco del mito, de la comedia [afirma De Beauvoir], pero es también un hecho que la mujer es más atenta que
} 


\section{en-claves}

arendtiana, la pérdida del sentido común que explica un aspecto esencial del fenómeno totalitario, es interpretada en estas páginas y situada en la relación entre los sexos, como una carencia histórica más amplia y determinante de lo que advirtió Arendt. La desigualdad entre hombres y mujeres da lugar a expresiones de inhumanidad y destrucción de la vida social no percibidas ni analizadas frecuentemente, aun cuando forman parte del sentido profundo de la condición humana desvelada magistralmente por ella.

En este caso, el eje del trabajo es la desigualdad de poder simbólico entre hombres y mujeres. El fenómeno incuestionado de la prostitución y las prácticas de violencia que se derivan y se magnifican a partir de la tolerancia a ella, definen el horizonte de degradación humana que presenciamos. Pero el despliegue imperceptible de múltiples formas de violencia simbólica y sexual contra las mujeres puede ser enfrentado críticamente y deconstruido conceptualmente con el portentoso pensamiento de filósofas que vinculan la razón con el amor al mundo, como las que fundamentan el presente trabajo. Abordamos algunos de los aportes de las filósofas referidas a la vida contemporánea sobre el amor, la comprensión y el milagro, en dos apartados.

En el primero revisamos algunos problemas de nuestro tiempo que ameritan una indagación de tipo filosófico más profunda que la que hacen las ciencias sociales. La decadencia de la vida social signada por problemas relativos a las relaciones humanas de pareja y otras formas conflictivas de relación entre hombres y mujeres niega el principio de igualdad e impone una representación asimétrica de los sexos, con base en un concepto patriarcal de autonomía que degrada la condición humana de las mujeres. Por ello, establecemos aquí la importancia, el marco teórico, los objetivos, los temas y el propósito de este abordaje, mediante un análisis introductorio de algunos conceptos relevantes de la filosofía feminista y siguiendo el problema - emergente en el siglo XX - de la autonomía y del amor.

El segundo apartado consiste en un análisis crítico de algunos conceptos arendtianos útiles para la problematización de nuestro presente. La superación del mal radical se sustenta en la posibilidad del milagro que los seres humanos representan, y éste parece ser casi el único recurso para la reconstrucción de un sentido común que integre a las mujeres.

el hombre para consigo misma y el mundo". Simone de Beauvoir, El segundo sexo II. La experiencia vivida (Buenos Aires, Siglo XX, 1981), 407-408. 


\section{enn-claves}

Buscamos aplicar algunas ideas del pensamiento político de Arendt, y otras complementarias de Simone Weil a la realidad actual, así como a las disputas que inferiorizan a las mujeres sobre la base de los planteamientos de Simone de Beauvoir.

\section{El problema de la autonomía y el amor}

Con el fin de pensar una posible solución a la evidente expansión de la vida en el desierto tomamos como ejemplo de pérdida del sentido común — que constituye el rasgo más claro del totalitarismo residual del siglo XXI - algunos asuntos representativos del sistema de desigualdad sexual legitimado durante milenios, que hoy nos corresponde intentar desestructurar. Tales asuntos son: el acoso sexual y la subsecuente disputa, iniciada por el movimiento Me Too; ${ }^{6}$ la proliferación de violaciones tumultuarias ${ }^{7}$ que se cometen a la luz del día, a veces exhibidas públicamente en medios electrónicos; el antiguo problema de una supuesta legitimidad de la prostitución que divide a defensores y detractores en regulacionistas y abolicionistas; y la polarización entre convencidas y disidentes de la llamada responsabilidad afectiva, en el núcleo de la discusión acerca de nuevas formas de relaciones sexo-afectivas como el poliamor. ${ }^{8}$

Nuestro objetivo es pensar e intentar extraer algunas implicaciones filosóficofeministas de los conceptos de sometimiento y de poder involucrados en la relación amorosa (y algunas derivaciones de ésta en formas de violencia) que nos permitan liberar las prácticas humanas y sus afinidades intersubjetivas de la confusión comúnmente establecida en torno al acto humano (no sólo feminista) del consentimiento. La base de nuestro argumento son las discusiones sobre el acoso sexual y la respuesta práctica del escrache, que consiste en una exhibición pública de sujetos acusados de ser agresores. Las

\footnotetext{
${ }^{6}$ Valentina Ramírez, “Te explicamos/Me too: ¿Por qué surge este movimiento y qué sigue?”, La voz de Michoacán, 3 de abril 2019, https://lavozdemichoacan.com.mx/pais/teexplicamos-me-too-por-que-surge-estemovimiento-y-que-sigue-para-sus-involucrados/.

${ }^{7}$ Cfr. Diversas publicaciones periódicas. Entre otras: EFE, "Violaciones grupales: 37 'manadas' en 8 meses", Levante. El mercantil valenciano, 2 de agosto de 2019, https://www.levante-emv.com/sucesos/2019/08/02/violaciones-espana-manadas-agresionessexuales/1907617.html?fbclid=IwAR1yZTIW8Xq2aAMUEPA1ScSveLKaYeZBJW4ObgvasT2A5zJ4iXhlIK1 Q-CM.; y Gerardo Jiménez, "Policías someten y violan a menor en Azcapotzalco", Excélsior, 7 de agosto de 2019 , https://www.excelsior.com.mx/comunidad/policias-someten-y-violan-a-menor-enazcapotzalco/1328672.

8 "Acostarse con un boludo no es violencia", Entrevista a Alexandra Kohan por Agustina Escobar, Panamá. No todo es política, 6 de junio de 2019, http://www.panamarevista.com/acostarse-con-un-boludo-no-esviolencia/.
} 


\section{en-claves}

denuncias realizadas — muchas veces anónimamente - por quienes defienden la integridad de sus cuerpos se han enfrentado a la postura de actores sociales masculinos que aseguran que "ya les da miedo hasta saludar" o "decirle 'guapa' a una mujer", y a las afirmaciones de quienes, con pretendida o real ingenuidad, sostienen que, como no se han establecido nuevas formas de trato, las formas tradicionales de coqueteo son malinterpretadas por feministas extremistas como acoso.

Como si entre los hombres y las mujeres existiera una barrera que divide la significación frente a los mismos hechos, sin permitir una comprensión común de la experiencia, los pseudoargumentos que se esgrimen son un ejemplo de lo que Arendt denomina "pérdida del sentido común", y que el feminismo teórico constata reiteradamente como una ausencia histórica del mismo. No ha habido en la historia humana afinidad total del sentido común de hombres y de mujeres más allá de los momentos en los que ellas se encuentran sometidas al sentido general de lo humano que los varones han representado, usurpando así el sentido auténtico de lo humano, que, para serlo, debería incluir la perspectiva de las mujeres. ${ }^{9}$ Desde este enfoque es hasta cierto punto fácil identificar las críticas masculinas como formas medrosas o maliciosas de justificación de comportamientos avasallantes que las mujeres tienen que soportar sin mediación, en la medida en que la tradición que apoya tales prácticas y argumentos convalida una acepción consensada históricamente sobre el abordaje amoroso, sin la participación de las mujeres.

La antropóloga feminista Rita Segato confirma que el carácter androcéntrico de la cultura es sostenido y reforzado por una tradición que anula la experiencia y el significado humano de las prácticas femeninas. La violación cruenta representa para ella la esencia de lo irracional, en la medida en que no tiene finalidad ulterior desde un punto de vista pragmático. Su única función socialmente hablando es revelar un ejercicio de poder y de control sólo inteligible entre varones y desde la lógica patriarcal. ${ }^{10}$ En el mismo sentido,

\footnotetext{
${ }^{9}$ De hecho, De Beauvoir sostiene que las mujeres podemos ser más auténticas: “Como [la mujer] se halla mal adaptada a la sociedad de los hombres, a menudo se ve obligada a menudo a inventar sola su conducta, y se contenta menos que ellos con recetas preparadas o clisés. Si es de buena voluntad, hay en ella una inquietud más cercana de la autenticidad que la seguridad importante de su esposo". De Beauvoir, El segundo sexo, 408.

${ }^{10}$ En referencia específica a la violación, dentro de su interpretación sobre la violencia contra las mujeres (aquí incluimos el feminicidio y la prostitución), Rita Segato afirma que "el acto cometido apunta ahora al disciplinamiento de una mujer genérica y ya no concreta, o implica un desafío dirigido a otro hombre también sin identidad definida [... Se trata, dice, de la manifestación de] una estructura anclada en el terreno de lo simbólico y cuyo epifenómeno son las relaciones sociales, las interacciones concretas entre hombres y
} 


\section{enn-claves}

Marilyn Frye sostiene que toda la cultura es homoafectiva, ya que cultiva sólo el amor por los hombres.

Decir que un hombre es heterosexual implica solamente que él tiene relaciones sexuales exclusivamente con el sexo opuesto, o sea, mujeres. Todo o casi todo lo que es propio del amor, la mayoría de los hombres hetero lo reservan exclusivamente para otros hombres. Las personas que ellos admiran, respetan, adoran y veneran, honran; quienes ellos imitan, idolatran y con quienes cultivan vínculos más profundos; a quienes están dispuestos a enseñar y con quienes están dispuestos a aprender; aquellos cuyo respeto, admiración, reconocimiento, honra, reverencia y amor ellos desean: éstos son, en su enorme mayoría, otros hombres. En sus relaciones con mujeres, lo que es visto como respeto es cortesía, generosidad o paternalismo; lo que es visto como honra es colocar a la mujer como en una campana de cristal. De las mujeres ellos quieren devoción, servidumbre y sexo. ${ }^{11}$

La diferencia de interpretación que hombres y mujeres llegan a tener sobre los mismos hechos es frecuente, pero el rechazo a las denuncias por abuso sexual llega a ser asumido también públicamente por algunas mujeres. Ante la falta de recursos legales efectivos existentes en una tradición cultural que durante siglos ha desconocido la dignidad humana de las mujeres, el movimiento en torno a la legítima posibilidad de libertad sexual de las mujeres conocido como Me Too, iniciado por actrices norteamericanas que se atrevieron a denunciar situaciones de acoso insostenible a raíz de múltiples abusos sexuales experimentados sobre sus cuerpos durante décadas, tuvo una respuesta de 100 artistas francesas titulada "Contra el puritanismo sexual", que convalida las críticas masculinas recurrentes, y que entre otras cosas dice:

Esta justicia expeditiva ya tiene sus víctimas: hombres sancionados en el ejercicio de su profesión, obligados a renunciar, etc.; mientras que ellos sólo se equivocaron al tocar una rodilla, tratar de robar un beso, hablar sobre cosas 'íntimas' en una cena de negocios, o enviar mensajes sexualmente explícitos a una mujer que no se sintió atraída por el otro. ${ }^{12}$

mujeres históricos". Rita Segato, Las estructuras elementales de la violencia (Buenos Aires: Universidad Nacional de Quilmes, 2003), 26.

${ }^{11}$ Marilyn Frye, Politics of Reality: Essays in Feminist Theory, (Trumansburg, NY: Crossing Press, 1983), 134-135.

12 "El manifiesto completo de las intelectuales francesas contra el Me too", 9 de enero 2018, Infobae, https:/www.infobae.com/america/mundo/2018/01/09/el-manifiesto-completo-de-las-intelectuales-francesascontra-el-metoo/. 


\section{enn-claves}

Hemos de convenir que la crítica de la desigualdad nunca ha sido conformada por un bloque homogéneo que incluya a todas las mujeres. La polarización de las posturas activas frente al tema de acoso y la más antigua referente a la prostitución remiten a una manera diversa de enfrentar la desigualdad en función del dolor experimentado y a la manera de concebir procesos de emancipación e ideologías de sometimiento. En el documento de réplica de las europeas parece justificarse la posibilidad de acercamientos sexuales indeseados que obstruyeron las legítimas aspiraciones laborales de las actrices norteamericanas que denunciaron el acoso. Y aquí radica la importancia del análisis conceptual del consentimiento, que en este punto conecta con el tema de la ausencia de sentido común, en torno al carácter voluntario de las relaciones humanas entre hombres y mujeres.

Lo que las viejas europeas califican como linchamientos hacia los varones, las jóvenes artistas norteamericanas lo conciben como una respuesta legítima, dado el contexto de descrédito que tiene la palabra de las mujeres ante la ley, frente a acciones cuestionables de violencia y abuso injustificable (según ellas) desde cualquier punto de vista. Las actrices de Hollywood caracterizan la actuación de esos varones poderosos de la industria cinematográfica como coerción abierta o intimidación sutil, mediante la que lograron o intentaron un acceso carnal indeseado por ellas, lo que pone en cuestión la autonomía de unas o de otros.

Otro efecto de la degradación sistemática de la vida social característica del siglo XXI que es necesario analizar, sobre todo debido al incremento que posteriormente ha tenido, son las conductas criminales de violadores tumultuarios entre los que destaca el ataque a una joven de 18 años por parte de 5 hombres autodenominados La manada, ocurrido durante las fiestas de San Fermín en julio de 2016 en España, y el abuso cometido contra una menor de edad por parte de otro grupo denominado Los porkys o Chacales de costa de oro, en el estado de Veracruz, México, en enero de 2015. ${ }^{13}$ A lo largo de la historia son recurrentes los antecedentes de estos hechos cruentos, como el dramático caso de la periodista mexicana y defensora de los derechos humanos Lydia Cacho Ribeiro en su enfrentamiento con la red de pederastia mexicana, cuando en 2004 reveló un vínculo entre

\footnotetext{
${ }^{13}$ Cfr. Estefanía Vela, “Caso 'Porkys', Explicación y análisis de la (indignante) sentencia”, Nexos, 29 de marzo de 2017), https://eljuegodelacorte.nexos.com.mx/?p=6492.
} 


\section{en-claves}

empresarios y políticos en su libro Los demonios del edén. ${ }^{14}$ Lo diferente en los últimos tiempos es la ostentación y el orgullo cínico con que los crímenes sexuales han sido progresivamente asumidos.

A diferencia de los crímenes sexuales del pasado — por más violentos e indignantes que resulten - las violaciones tumultuarias de hoy son inclusive mostradas en las redes sociales electrónicas, lo que parece una amplificación simbólica de la violación normalizada de los cuerpos de mujeres en la prostitución. La concepción histórica de esta práctica presume el ejercicio de una decisión libre que es producto de la simple voluntad individual de las prostitutas, ${ }^{15}$ quienes inclusive son juzgadas como inmorales en documentos que se consideran sagrados, a través de "preceptos culturales, justificados incluso en libros como La Biblia y El Corán [en los que] se califica a las mujeres sexo servidoras - que en su gran mayoría entran a la prostitución de manera forzada - como seres desechables, inferiores y sucios que merecen el desprecio de la sociedad", ${ }^{16}$ sin considerar el hecho de pobreza que deriva de una estructura de desigualdad y la carencia de alternativas de sobrevivencia que son parte fundamental de su existencia.

El consumidor de cuerpos se caracteriza justamente por la posibilidad de contar con recursos económicos que le colocan precisamente en el papel de consumidor y no como producto de compra-venta. La periodista torturada por la revelación de sus investigaciones sobre pederastia se pregunta por las causas de la normalización del comercio sexual, y su respuesta es ilustrativa de cómo la prostitución (femenina) es naturalizada en la historia y concebida como práctica inevitable que se sustenta en creencias tradicionales sobre la incontinencia de los varones (a veces también utilizada como justificación de la violación), en cuya base descansa la inexistencia de la dignidad humana de las mujeres. Por ello afirma:

Prácticamente en todas las culturas de oriente y occidente la sexualidad humana tiene, incluso en pleno siglo XXI, una carga de tabú que le permite sostenerse sobre argumentos biologicistas anacrónicos, [...] el primordial es que a hombres y mujeres por igual suele educársenos con base en la teoría de que ellos tienen una necesidad sexual biológica de tal magnitud que justifica que

\footnotetext{
${ }^{14}$ Lydia Cacho, Los demonios del edén (México: Grijalbo, 2006).

${ }^{15}$ No les llamamos "trabajadoras sexuales" debido a que rechazamos normalizar dicha práctica.

${ }^{16}$ Cacho, Los demonios, 173.
} 


\section{enn-claves}

realicen actos como el de comprar sexo a terceros y forzar a sostenerlo a personas que no lo desean o que los rechazan. ${ }^{17}$

Las y los defensores del comercio sexual llegan incluso a definir la prostitución como un trabajo equiparable a otras formas de explotación no vinculadas con el erotismo. Sus argumentos presumen actuaciones autónomas de los participantes. En contra de la propuesta de regular la compra-venta de cuerpos se encuentra la postura abolicionista que propone prohibirla, y otra intermedia, respetuosa de los derechos individuales, pero de defensa colectiva de las mujeres, que cuestiona la trata de personas con fines de explotación sexual y consiste en la idea de limitar el consumo, combatir la explotación y sancionar toda forma de participación en el delito. Se mantiene al margen de prohibir la práctica (supuestamente, autónoma) de la prostitución, aunque sigue considerándola humanamente indigna.

Finalmente, más allá de las discusiones, polarizaciones políticas y hasta de los efectos concretos de sucesos demoledores socialmente (como la proliferación de violaciones y asesinatos de mujeres con grados de crueldad inimaginables) en el campo de la psicología también se han desplegado posiciones polares ante nuevas formas de interacción amorosa voluntaria que rompe con el principio de exclusividad: el poliamor, que consiste en establecer relaciones abiertas a la posibilidad de múltiples parejas sexuales. Las uniones de este tipo son concebidas de acuerdo con valores aparentemente inconciliables: la autonomía y el apego, que se sostienen en correlativos conceptos de amor prescritos ante inéditas formas de interacción humana surgidas a la luz de la diversidad sexual, y que reconfiguran nuevos modos de comprender el mundo.

La disyuntiva que las participantes en la discusión proponen es, por un lado, la defensa de una autonomía personal absoluta y, supuestamente, incuestionable versus una posible relación recíproca de respeto emocional y responsabilidad ante las necesidades afectivas del otro. Llamaremos a la primera posición 'autonomista' y a la segunda 'corresponsable' o 'recíproca'. La primera postura (autonomista), basada en la teoría psicoanalítica lacaniana, sostiene que no es posible responsabilizar al otro de las necesidades afectivas de las personas. La segunda posición (recíproca), que puede asociarse

\footnotetext{
${ }^{17}$ Ibidem.
} 


\section{enn-claves}

al despliegue de la teoría de la diferencia sexual, se basa en una crítica del abuso emocional que es validado en la desigualdad sexual en la que se sostienen las relaciones afectivas.

El debate se centra en lo que se denomina "responsabilidad afectiva". ${ }^{18}$ Concepto que involucra la necesidad de reciprocidad y cuidado afectivo en nuevas formas de establecer acoplamientos abiertos a la posibilidad de otros contactos sexuales o afectivos. La propuesta consiste en postular reglas de comportamiento moral para los amantes, condicionando la posibilidad de amor auténtico al criterio básico de la reciprocidad. En contra, la postura autonomista concibe el deseo sobre una base de ambigüedad que surge del inconsciente, y ello le autoriza a adjudicar responsabilidad total a cada amante y rechazar cualquier posible exigencia afectiva, que se considera como expresión de apego. ${ }^{19}$

La posición recíproca, que es contraria a la postura psicoanalítica descrita, que se sostiene en el criterio de la autonomía personal, se sitúa en coincidencia con las defensoras del movimiento Me Too, esto es, en el orden de una intersubjetividad equilibrada e igualitaria que se abre a la posibilidad de una autonomía amorosa mediada por vínculos de reciprocidad afectiva. La responsabilidad afectiva (entre dos personas o entre varias) enlaza su crítica de la desigualdad de género con los rasgos de personalidad dominante y dominada, alimentadas socialmente en una sociedad cuyo eje es la competencia, y describe el entramado del enlace autónomo (altamente conflictivo y doloroso emocionalmente) como un peligroso sustituto de lo que debería ser un verdadero encuentro afectivo.

Bajo una interpretación de hechos que reduce a las mujeres a cuerpos (objeto) consumibles, en todos los casos de encuentro sexual — como si no hubiera diferencia entre relaciones amorosas voluntarias y relaciones forzadas como la violación, el acoso sexual o el ejercicio de venta y consumo sexual-, la posición autonomista y la de las artistas europeas críticas del Movimiento Me Too coinciden en su defensa del intercambio o el comercio sexual de cuerpos como un ejercicio de autonomía por ambas partes. En todos los casos la apelación al criterio de autonomía personal, que excluye total responsabilidad frente a las otras personas, implica justificar moralmente la violencia, elimina la responsabilidad social frente a hechos que constituyen delito, permite interpretar la

${ }^{18} C f r$. Magdalena López, "Por una pedagogía del cuidado, el acuerdo y la responsabilidad afectiva", LATFEM Periodismo feminista, 8 de junio de 2019, https://latfem.org/por-una-pedagogia-del-cuidado-elacuerdo-y-la-responsabilidad-afectiva/?fbclid=IwAR2hEKPwR41tn03TzeUk5_SSnqtdZKdulGEdK4fOydfXwSFEeYW4W6sBUs.

19 "Acostarse con un boludo". 


\section{enn-claves}

coerción (económica o de cualquier tipo) como consentimiento y termina responsabilizando a las mujeres de la dominación que padecen.

Un ejemplo claro de la patente cercanía del desierto contemporáneo representativo del mal radical de nuestro tiempo son los deficientes o nulos procesos de investigación y sanción en infinidad de casos de violencia sexual, ${ }^{20}$ como las denuncias de pederastia que hiciera hace casi quince años Lydia Cacho y lo poco que se ha hecho al respecto. La impunidad de los delitos sexuales es un rasgo dominante de una cultura de desigualdad y discriminación, ciega ante las injusticias contra las mujeres. Por último, como asegura la periodista Lydia Cacho (víctima de persecución y de tortura), la mayor parte de lo mucho que se ha escrito sobre el tema de prostitución y pederastia se centra en el dolor de las víctimas y no en los perpetradores: “esos millones de hombres de negocios, padres de familia, políticos, policías, curas, obispos, maestros, rabinos, empresarios y estudiantes, que a diario buscan comprar sexo, activando así uno de los negocios más rentables del mundo después del narcotráfico". ${ }^{21}$

A esto se refiere el cuestionamiento que hacemos acerca de la pérdida de sentido común, cuya vigencia apabullante sostiene el incremento de la violencia en este siglo. El individualismo moderno, reforzado por la cultura patriarcal, es responsable de la inconcebible pérdida de sentido que define nuestro presente debido al carácter contradictorio del patriarcado. Además de ser los principales consumidores, según datos oficiales registrados por Lydia Cacho, son hombres quienes controlan, coordinan y protegen el 90 por ciento del negocio de la prostitución. Este punto - junto con el abortotambién es ilustrado por la madre del feminismo contemporáneo como duplicidad de un sentido establecido que no se respeta, cuando dice que

\footnotetext{
${ }^{20} C f r$. Redacción, "Joven que denunció violación por policías en CdMx perdió confianza en investigación por filtración de autoridades", Aristegui Noticias, 9 de agosto de 2019, https://aristeguinoticias.com/0908/mexico/filtracion-causo-perdida-de-confianza-de-joven-que-denuncioviolacion-de-policias-pero-investigacion-sigue-pgj/; Sujeyry Gándara, "PGJ: Policías de CdMx señalados de violar a joven no están imputados, y saldrían libres", Sin embargo.mx, 8 de agosto de 2019, https://www.sinembargo.mx/08-08-2019/3625820; y Redacción, "5 años de cárcel y 70 pesos, la sentencia de uno de 'Los Porkys'; apela fiscalía de Veracruz", Aristegui Noticias, 9 de agosto, 2019, https://aristeguinoticias.com/0908/mexico/5-anos-de-carcel-y-70-pesos-la-sentencia-de-uno-de-los-porkysapela-fiscalia-de-veracruz/.

${ }^{21}$ Cacho, Los demonios, 172.
} 


\section{enn-claves}

Ya se ha visto con qué hipocresía decretan los hombres que el aborto es criminal, cuando todos los años hay en Francia un millón de mujeres a quienes el hombre ha puesto en situación de abortar [...] El ejemplo más flagrante de esta duplicidad es la actitud del varón ante la prostitución: su demanda es la que crea la oferta $[\ldots]$ se considera que son perversas y depravadas las muchachas que viven de su cuerpo, pero no los varones que lo usan. ${ }^{22}$

En coincidencia con Simone de Beauvoir y con Sor Juana Inés de la Cruz, quien desde el siglo XVII sostuviera: "O cuál es más de culpar, aunque cualquiera mal haga: la que peca por la paga, o el que paga por pecar", ${ }^{23}$ ilustrando la inhóspita extensión del desierto que nos envuelve y que invisibiliza el oasis del pensamiento de las grandes pensadoras que han cuestionado la práctica de la prostitución, la escritora de Los demonios del edén refiriere a grandes novelistas de alma masculina que subliman a través de la literatura la violencia contra las mujeres y glorifican la prostitución, describiendo ambientes sórdidos y personajes interesantes que se enamoran de prostitutas "sucias y sensuales" a las que desprecian por "putas". En su penetrante descripción, Lydia Cacho destaca la insólita reseña de Lolita (donde el personaje de cincuenta años de edad se enamora de una niña de doce años): "considerada una joya literaria, está clasificada como 'una obra literaria de erotismo sublime", ${ }^{24}$

Comprender implica fundamentalmente dar un lugar adecuado a los conceptos. La añeja práctica de naturalizar transacciones de cuerpos femeninos hace de la prostitución un ejercicio público: secreto a voces que casi nadie se atreve a cuestionar, y menos aún la posición tan reprochable del consumidor de cuerpos. Inclusive hay gobiernos que regulan la prostitución femenina, colocándose en un papel similar al proxeneta. "Se naturaliza un delito contra las mujeres y las niñas y niños al grado de que dicho negocio está reglamentado o legalizado en diversos países del mundo", ${ }^{25}$ afirma Cacho, exponiendo el

\footnotetext{
22 "A fines del siglo pasado la policía descubrió en un prostíbulo a dos niñas de doce y trece años; hubo un proceso en el cual ambas declararon y hablaron de sus clientes, que eran señores importantes, y una de ellas abrió la boca para decir su nombre. El procurador general la detuvo precipitadamente: ¡No manches el nombre de un hombre honesto! Un señor condecorado con la Legión de Honor sigue siendo un hombre honesto, aunque se acueste con una niña de tierna edad. Tiene sus debilidades, pero ¿quién no las tiene? En tanto que la pequeña ramera, que no accede a la región ética de lo universal [como sostuvo Hegel] — que no es un magistrado, ni un general, ni un gran francés, sino solo una pequeña ramera-, se juega su valor moral en la región contingente de la sexualidad, y es una perversa, una desviada, una viciosa que debe estar en una casa de corrección". De Beauvoir, El segundo sexo, 397.

${ }^{23}$ Sor Juana Inés de la Cruz, "Redondillas”, Obras completas (México, Porrúa, 1996), 109.

${ }^{24}$ Cacho, Los demonios, 182-183 (Los subrayados son propios).

${ }^{25}$ Ibidem.
} 


\section{enn-claves}

vínculo profundo entre explotación sexual infantil y normalización de la violencia de la venta de cuerpos.

El hecho de que algunas víctimas del pederasta Jean Succar (quien explicaba en un video cómo violaba bebés de dos años) actualmente preso, después de la investigación de Lydia Cacho, aceptaran dinero o regalos, permitió a su defensa esgrimir sus dádivas como justificación: “"Es simple prostitución', dijeron a la prensa” ${ }^{26}$ Según la propia visión del pederasta, como dice Lydia Cacho,

no es, por tanto, ni bestia ni monstruo; es un hombre normal (porque entra en la norma) que durante más de veinte años abusó de niñas y niños [de hasta cinco años...], en sus propias palabras, 'sus putitas' [...]. Él, como millones de hombres en todo el orbe que pagan a lenones por tener sexo con jovencitas o con niñas, afirma que éstas son prostitutas, y dado que la prostitución es un negocio mundial perfectamente legal, ¿cuál es el problema? ${ }^{27}$

El problema es que, sin un mismo sentido de realidad compartido por hombres y mujeres, el mundo es un espacio de confusión y desorientación que inhibe la posibilidad misma de la acción. La existencia de ambos se reduce a un mundo de objetos donde los referentes de la pluralidad resultan caóticos e incomprensibles ante la falta de consenso sobre lo que es correcto o deseable para todas las personas. Esto es lo que ilustra la pérdida de mundanidad o de sentido común (que según Arendt es la base para que cosas como el nazismo pudieran ocurrir). En la prostitución como en el acoso, en la violación y en la postura autonomista del deseo que rechaza la responsabilidad afectiva, se pone en juego la insensibilidad ante la humanidad del otro. El desierto del germen totalitario se sigue extendiendo, anulando la posibilidad de que el siglo XXI sea un oasis.

Por otra parte, reconocer lo correcto y lo incorrecto implica sobre todo evitar daños. En este caso, lo que está en juego es la necesidad de comprender que la autonomía esgrimida implica rechazar cualquier tipo de coerción sobre las personas. No es correcto refugiarse en la idea o imponer la violencia simbólica de una supuesta autonomía que representa nuevas formas de aislamiento y un reforzamiento de la crueldad, ya que como

\footnotetext{
${ }^{26}$ Ibid., 175.

${ }^{27}$ Ibid., 180-181.
} 


\section{en-claves}

afirma Hannah Arendt, "el peligro consiste en que nos convirtamos en verdaderos habitantes del desierto y nos sintamos cómodos en él". ${ }^{28}$

\section{Comprensión y milagro}

El concepto de mundanidad de Hannah Arendt, el rasgo inhóspito de la realidad producido por el mundo de cosas fabricado por los seres humanos, es tan relevante como el amor al mundo [amor mundi] ya que, siendo contrarios, ambos constituyen el suelo propio de la política. La mundanidad es el medio en el que se desarrolla la vida humana con sus posibilidades de grandeza y superación del mal, o bien de limitación y decadencia de las posibilidades de igualdad y libertad (que son condición para la acción política).

La política constituye la fuente de posibilidad que los seres humanos tienen para sobrevivir, y su ausencia: la vía para la posible extinción de la vida humana; en ello radica su valor. La posibilidad de realización de la política está situada en el entre de los vínculos humanos cuya condición es la pluralidad, y su función es garantizar la sobrevivencia de la vida humana y la preservación del mundo (que es el espacio construido por los seres humanos, en donde se posibilita la acción). Pero la comprensión, que es para Arendt junto al discurso - la otra cara de la acción, resulta ineludible. En el texto referido al inicio de este trabajo la filósofa alemana cuestiona la utilidad de la psicología para enfrentar el problema del totalitarismo residual que marca las relaciones humanas de nuestro tiempo. La psicología moderna — dice — es psicología del desierto en la medida en que su objetivo es que nos adaptemos a él en lugar de que intentemos transformarlo; como se muestra en las posiciones que postulan la inevitabilidad de las relaciones destructivas (concepción autonomista) debido al rasgo de ambigüedad del deseo.

Cuando perdemos la facultad de juzgar, 'de sufrir y de condenar' [... de separar el bien del mal, diría Simone Weil en concordancia con Arendt], ${ }^{29}$ comenzamos a pensar que hay algo equivocado en nosotros si no podemos vivir bajo las condiciones del desierto. [Y] en la medida en que la psicología trata de 'ayudarnos' nos ayuda a 'ajustarnos' a aquellas condiciones y nos quita nuestra única esperanza; a saber: que nosotros, que no somos del desierto aunque vivamos en él, somos capaces de transformarlo en un mundo humano. ${ }^{30}$

\footnotetext{
${ }^{28}$ Arendt, "Del desierto".

${ }^{29}$ Simone Weil, A la espera de Dios (Madrid: Trotta, 1993), 120.

${ }^{30}$ Arendt, "Del desierto".
} 
Así, atendiendo a la indicación de no ajustarnos a las condiciones del desierto, en este apartado nos remitimos a la distinción que Arendt establece entre 'comprensión' y 'perdón'; analizamos su concepto de reconciliación, y establecemos una analogía (de sus postulados) con el tema feminista del consentimiento, señalando algunos paralelismos y contradicciones. Reconocer el campo de posibilidad humana de la acción —actualmente limitada por el desierto del mal radical del siglo XXI: la violencia sexual- $-\mathrm{y}$ su vínculo efectivo con la comprensión, que es para Arendt un elemento sine qua non de la vida política, implica centrarnos en el asunto gnoseológico-ontológico de la reconciliación distinguiéndolo del nivel ético-político del perdón. Aunque, propiamente, en el pensamiento de Arendt los niveles gnoseológico y ético resultan prácticamente indiscernibles.

En franca crítica a los pensadores profesionales, la pensadora del totalitarismo propone, en referencia al rey Salomón, la necesidad de juzgar a través de un corazón inteligente, como el medio para alcanzar una verdadera comprensión del mundo. La solución de la filósofa a las complejas conexiones establecidas en el mundo de los asuntos humanos es que "ni la pura reflexión ni el simple sentimiento sino sólo 'un corazón comprensivo' nos hace soportable el vivir en un mundo común, con otros que siempre son extraños, y nos hace asimismo soportables para ellos". 31 En general, el colectivo de los hombres se liga con las mujeres violenta o amablemente, pero, generalmente, inferiorizándolas con un sentido a veces nada sutil de posesión.

Rita Segato sostiene que el significado de la violencia cruenta contra las mujeres es determinante de una masculinidad que construye el sentido profundo de lo masculino como violencia. "De improviso, un acto violento sin sentido atraviesa a un sujeto y sale a la superficie de la vida social como revelación de una latencia, una tensión que late en el sustrato de la ordenación jerárquica de la sociedad". ${ }^{32}$ Desde el sentido instrumental de la racionalidad patriarcal es claro que ni la rabia ni la violencia son necesariamente irracionales. La distinción arendtiana respecto a la violencia entre el mal que acontece naturalmente y el mal recibido como injusticia apunta al hecho de que la violencia se

\footnotetext{
${ }^{31}$ Hannah Arendt, De la historia a la acción (Barcelona: Paidós, 1995), 45

${ }^{32}$ Segato, Las estructuras elementales, 23.
} 


\section{enn-claves}

percibe como injustificable cuando se agrega el componente de lo voluntario, esto es, la decisión deliberada de dañar. ${ }^{33}$ Que la agresividad no es lo mismo que la violencia, como señala Arendt, es evidente en la violencia selectiva de los machos que —como señalan las feministas - no agreden a cualquiera sino a su propia pareja.

Ahora bien, los actos fundados en una elección incorrecta del bien y el mal entre hombres y mujeres, aunque por diversas razones lleguen a ser individualmente perdonados, no deberían serlo. Menos por la mayoría y mucho menos en un consenso casi universal expresado incluso silenciosamente- como ocurrió durante el período totalitario con el nazismo. Por el contrario, a pesar de la incertidumbre y las dificultades que caracterizan los espacios del amor y la amistad (cuya base debería ser el principio de reciprocidad), con todo y su ambigüedad, resultan ser imprescindibles. Sin ellos, dice Arendt, "sin la intangibilidad de esos oasis no sabríamos cómo respirar". 34 Pero si permitimos que el significado de los oasis se diluya, si no sabemos cómo usar los oasis que son la fuente de la creatividad personal, corremos el riesgo de asimilarnos al desierto; de convertirnos en sujetos adaptados al mundo, sin la capacidad crítica que permite pensar e innovar. Si no somos capaces de poner en cuestión las formas tradicionales de trato entre hombres y mujeres, corremos el riesgo de mantener las formas atroces y dolorosas de relacionarnos, y terminar por convertirnos en

habitantes del desierto, incluso sin ayuda de la psicología. En otras palabras, los oasis se secarán si no los mantenemos intactos, y ellos no son meros lugares de 'relax' sino las fuentes dispensadoras de vida que nos permiten vivir en el desierto sin reconciliarnos con él. ${ }^{35}$

En este sentido todas las formas de relación que sostienen la necesidad de mantener intacto el ejercicio de la violencia sobre los cuerpos femeninos, sin ningún tipo de

\footnotetext{
${ }^{33}$ En contra de lo que comúnmente piensan los glorificadores de la violencia como regeneradora de la vida, y distinguiendo la agresividad (que compartimos todos los animales) de la violencia como específicamente humana y racional, dice Arendt: "El más claro signo de deshumanización no es la rabia ni la violencia sino la evidente ausencia de ambas. La rabia no es en absoluto una reacción automática ante la miseria y el sufrimiento como tales; nadie reacciona con rabia ante una enfermedad incurable, ante un terremoto o, por lo que nos concierne, ante condiciones sociales que parecen incambiables. La rabia sólo brota allí donde existen razones para sospechar que podrían modificarse esas condiciones y no se modifican". Hannah Arendt, Sobre la violencia (Madrid: Alianza, 2005), 85.

${ }^{34}$ Arendt, "Del desierto".

${ }^{35}$ Ibidem.
} 


\section{en-claves}

responsabilidad y bajo una aceptación acrítica de la autonomía absoluta del deseo masculino, que supuesta o realmente asumen las mujeres, corren el riesgo de convertirnos en habitantes permanentes del desierto. Para analizar a mayor profundidad esto, es necesario establecer en principio que ceder (conceder mediante un ejercicio de presión exterior) es diferente de consentir, que es la disposición auténticamente afirmada de un deseo personal. Esto coloca la idea de concesión, la acción de conceder, en oposición al consentimiento, como dos formas de aproximación e interacción personal que sólo bajo el criterio absoluto de un dominio masculino incuestionado pueden confundirse.

Conceder (o ceder) es una forma de negación, de autonegación del propio deseo que se constriñe, voluntariamente o no, frente al deseo del otro. Consentir es, por el contrario, aceptar sintiendo; afirmar con toda el alma el deseo propio, no a costa ni frontalmente sino en encuentro y coincidencia con el deseo del otro. La concesión es la forma de trato humano producido por la unilateralidad del deseo del sujeto dominante. El consentimiento es en cambio una forma de vincularse plena y efectivamente con otra persona mediante un deseo común, recíproco, que no niega ni asume el de ninguno de los participantes. En el mismo sentido o en uno semejante podemos colocar la trama arendtiana de la reconciliación y el perdón, asociando la primera con la comprensión que está ubicada en el orden intelectivo o gnoseológico, y el segundo con la justificación que lo coloca en un orden moral.

Arendt establece su axioma de la comprensión como reconciliación, y lo diferencia clara y explícitamente del perdón: “entender el totalitarismo no significa perdonar nada, sino reconciliarnos con un mundo en que cosas como éstas son simplemente posibles". ${ }^{36} \mathrm{La}$ comprensión permite aceptar lo que irrevocablemente ha ocurrido y reconciliarse con lo que inevitablemente existe, ${ }^{37}$ manteniendo un elemento de aceptación del orden del mundo en la medida en que la propia comprensión implica, de algún modo, una conciliación con él. La comprensión juega una especie de función redentora entre el mal del mundo y la persona. Sin embargo, la filósofa precisa que, a diferencia del perdón, que se ubica en el orden de la acción, ${ }^{38}$ la reconciliación, en un sentido más gnoseológico que moral, no significa justificar sino simplemente aceptar.

\footnotetext{
${ }^{36}$ Arendt, De la historia, 30.

${ }^{37}$ Ibid., 44.

${ }^{38}$ Ibid., 107.
} 


\section{enn-claves}

En este sentido, reconciliarnos con el mundo representa aquello que nos permite comprender, o reconocer aún los aspectos más negativos de la realidad. Pero sólo implica comprender, no perdonar, sino aceptar intelectualmente la realidad del hecho sin identificarse o asimilarse a él. Ante la posibilidad de una identificación personal o subjetiva con el hecho cruento (el fenómeno totalitario), Arendt sostiene una diferencia fundamental que le permite explicar su posición intelectual ante un fenómeno inaceptable moralmente, sin que esto implique considerarlo aceptable o asimilable a los valores de quien juzga la acción.

Por otra parte, sostener que la comprensión es lo único que podemos enfrentar al mal, involucra una implícita noción realista de verdad, en la medida en que la comprensión se refiere a la experiencia del mundo: "La comprensión, en suma, significa un atento e impremeditado enfrentamiento a la realidad, un soportamiento de ésta, sea como fuere". 39 Pero también postula una postura existencial irrecusable de reconocimiento crítico de la realidad, de aceptación del mundo sin resignación, sin asimilación y sin venganza. La experiencia personal ante la Shoah (el llamado Holocausto), lleva a la pensadora a sostener realistamente que

Comprender no significa negar lo que resulta afrentoso, deducir de precedentes lo que no tiene tales o explicar los fenómenos por tales analogías o generalidades que ya no pueda sentirse el impacto de la realidad y el choque de la experiencia. Significa, más bien, examinar y soportar conscientemente el fardo que los acontecimientos han colocado sobre nosotros $-\mathrm{y}$ no negar su existencia ni someterse mansamente a su peso como si todo lo que realmente ha sucedido no pudiera haber sucedido de otra manera. ${ }^{40}$

La pluralidad es para Arendt la condición desde la cuál las personas juzgan para actuar en un mundo en el que debemos aceptar que cosas terribles son posibles, pero ante las cuales es imposible someterse "mansamente a su peso" desde un punto de vista moral, como un "fardo que la realidad coloca sobre nuestros hombros", como afirma refiriéndose al realismo de un enfrentamiento con la realidad en un sentido intelectual. Sentido que,

\footnotetext{
${ }^{39}$ Hannah Arendt, Los orígenes del totalitarismo, Vol. I (México: Planeta-Agostini, 1994), 10 y 17.

${ }^{40}$ Hannah Arendt, Los orígenes del totalitarismo, (Madrid: Taurus, 1998), 8. (Los subrayados son propios). Desde una base claramente estoica, que conduce a la misma posición realista, Simone Weil también sostiene respecto al mal: "inclusive antes de haber dicho sí a su contrario, mantener la mirada fija en él para poder sentir repulsión”. Simone Weil, Pensamientos desordenados, (Madrid: Trotta, 1995), 48. Para ambas pensadoras se trata de discernir el mal antes de repudiarlo.
} 


\section{enn-claves}

aunque también involucra la dimensión existencial, precisamente por ello obliga a discriminar conscientemente la situación moralmente inaceptable. Así, podemos separar la comprensión como reconciliación con el mundo, del acto del perdón como justificación moral de las acciones. La reconciliación — a diferencia del perdón y en la medida en que conecta al sujeto con la facultad de comprender - significa reconocer la inevitabilidad de ciertos hechos del mundo; conceder en el entendido de que existen eventos que no podemos evitar, aunque moralmente es imperioso mantener que no es posible consentir ante ellos, esto es, aceptarlos o afirmarlos como buenos o correctos.

El perdón en cambio — debido a que corresponde al ámbito moral tanto como al político y social - implica reconocer la posibilidad de justificación moral ante hechos que están presentes debido al carácter impredecible de la acción o bien debido a las intenciones del agente. Lo imperdonable de las acciones es que ocurran a pesar de no ser inevitables, o que pudiendo haber sido de otra manera conduzcan a resultados cuestionables o inaceptables. En este sentido, la violencia exacerbada contra las mujeres, el hecho innegable de la existencia de interpretaciones antagónicas sobre el acoso y la violación, la alternativa de autonomía o explotación en las discusiones acerca de la prostitución, y, sobre todo, la necesidad de un esclarecimiento de los lazos afectivos entre hombres y mujeres en lo referente al amor — el acoso sexual por una parte y la responsabilidad afectiva por otra-, nos obligan a diferenciar conceptualmente los valores y significados involucrados en éstas y en otras prácticas que redefinen (permiten o limitan) las relaciones de pareja.

Todas las experiencias enumeradas están signadas por la falta de acuerdo, y profundamente instalada en las concepciones de la relación entre hombres y mujeres. Las relaciones jerárquicas por otra parte no son exclusivas de hombres y mujeres, aunque en ellas anide la primera experiencia de dominación, bajo la forma de una división sexual del trabajo que derivó en una jerarquía (social, simbólica y subjetiva). Ésta se expresa cualquier tipo de reparto social, como la clase y la etnia, donde la desigualdad está simbólicamente legitimada. Pero aún en estas relaciones se reitera el vínculo de dominación que caracteriza al género como el primer eje de distribución del poder.

Otro peligro representado en el desierto, más frecuente que la asimilación al mal de la violencia, es la indiferencia. "Porque aniquilamos los oasis dispensadores de vida cuando vamos a ellos con la intención de huir, parece a veces como si todo conspirase para 


\section{enn-claves}

generalizar las condiciones del desierto". ${ }^{41}$ La tolerancia ante el mal de la violencia sexual significa no reconocer efectivamente la autonomía del otro. La reconciliación permite ubicarse a resguardo de los peligros del perdón como asimilación al orden dado y la venganza como negación de la realidad. Los oasis representan la posibilidad de resistir ambos, al permitir al ser humano adaptarse a la vida inhóspita del desierto, provisionalmente, pero sin evadir su realidad. ${ }^{42}$ Según Hannah Arendt y Simone Weil es fácil que el discurso sea llevado a la demagogia - y a la ideología — cuando se separa de la necesaria relación con el mundo. Según ellas debemos pugnar siempre porque la palabra retorne a su lugar al lado de la experiencia. Afirma la primera: “¿cuál es el objeto de nuestro pensar? ¡La experiencia! ¡Nada más!”.43

En este sentido, Arendt apunta que de fondo no hay oposición entre verdad y opinión. Por esa razón tampoco debería existir contradicción entre la verdad histórica masculina y las opiniones femeninas frecuentemente descalificadas en contextos machistas y sociedades violentas de signo patriarcal. En la estructura dicotómica de la ideología patriarcal la designación de género coloca a las mujeres del lado de la subjetividad y a los varones del lado de la objetividad, y ello respalda las prácticas machistas que niegan valor de verdad a la palabra de las mujeres, como lo ejemplifica la práctica de la violación (uno de los delitos menos penalizados que existen en la sociedad por la falta de credibilidad que tienen las mujeres víctimas). ${ }^{44}$ Otro ejemplo de cómo las mujeres no son poseedoras de la verdad es la práctica conocida como mansplaining (denominada así por las feministas norteamericanas), que consiste en "explicar lo que las mujeres dicen".

Esta falta de reconocimiento de la humanidad de las mujeres es el resultado del profundo androcentrismo de las culturas patriarcales, cuya misoginia jerarquiza y atenúa la voz de las mujeres al identificar la objetividad con la mirada masculina. Su escasa participación en la ciencia, el arte, la filosofía, la política, deriva del hecho de que las mujeres carecen del reconocimiento de su subjetividad, como explica Simone de Beauvoir,

\footnotetext{
${ }^{41}$ Arendt, "Del desierto".

${ }^{42}$ Una forma más segura de destruir los oasis que la amenaza exterior de las tormentas de arena es la evasión: "Su nombre habitual es escapismo [...] Tratando de huir transportamos la arena del desierto a los oasis". Ibidem.

${ }^{43}$ Arendt, De la historia, 145.

${ }^{44}$ Tal situación de descrédito de la palabra femenina es señalada por Simone De Beauvoir a lo largo de $E l$ segundo sexo, como cuando describe la doble moral en la concepción de la prostitución. Cfr. Supra, nota 23. En éste (y en otros muchos casos) la descalificación de la palabra de la víctima no sólo la presenta como opinión, sino como opinión maliciosa o mentira.
} 


\section{enn-claves}

lo que implica que la voz de las mujeres, traducida como opiniones, no alcance el rango de verdad. El feminismo consiste precisamente en un cuestionamiento crítico de este dogma epistémico-político que sostiene las prácticas machistas, en culturas en las que los varones, por el contrario, se erigen en representantes privilegiados de una subjetividad supuestamente humana que se condensa lingüísticamente en la homonimia Hombre, que identifica al varón con la humanidad.

Para De Beauvoir,

uno de los beneficios que la opresión asegura a los opresores es que el más humilde de entre ellos se siente superior: un 'pobre blanco' del sur de los Estados Unidos tiene el consuelo de decirse que no es un 'sucio negro', y los blancos más afortunados explotan hábilmente ese orgullo. De igual modo, el más mediocre de los machos se cree un semidiós frente las mujeres. ${ }^{45}$

Ante lo desalentador de estas declaraciones debemos intentar desentrañar, con el apoyo de la filosofía feminista, la posibilidad de una comprensión de los hechos del mundo que sea común a hombres y mujeres. En el proceso de construcción de un sentido común que pueda integrar la experiencia plural de las relaciones entre ambos sexos se perciben diversos obstáculos; en principio, la propia idiosincrasia que remarca la condición de la pluralidad.

Para Hannah Arendt la falta de conciencia ante los hechos injustos de la colectividad deriva de la propia naturaleza de la doxa, que ella concibe como una base de experiencia. Sócrates, quien no renunciaba al hoy tan devaluado sentido común — que Arendt concibe como lo que asegura la posibilidad del juicio moral, la sabiduría misma en tanto forma compartida de virtud - consideraba la doxa, la opinión de los ciudadanos, como clave privilegiada para orientarse en torno a la acción moral y en la elucidación de la justicia. Dana R. Villa resalta que "la doxa no puede reducirse a unas sombras en la pared de la caverna ni a lo que 'los otros' piensen. Y su falta de validez universal no la convierte

\footnotetext{
${ }^{45}$ Las palabras del periodista francés Claude Mauriac, quien había escrito: “"Escuchamos con un tono [isic!] de indiferencia cortés... a la más brillante de ellas, sabedores de que su espíritu refleja de manera más o menos deslumbrante ideas que provienen de nosotros' [hacen decir a la filósofa:] No son las ideas de Claude Mauriac en persona, evidentemente, las que refleja su interlocutor, puesto que no se le conoce ninguna; es posible que ella refleje ideas que provienen de los hombres; entre los mismos machos hay más de uno que considera suyas opiniones que no ha inventado; es posible preguntarse, entonces, si Claude Mauriac no tendría interés en entretenerse con un buen reflejo de Descartes, de Marx o de Gide, antes que consigo mismo; lo notable es que pormedio del equívoco del nosotros, se identifique con San Pablo, Hegel, Lenin y Nietzsche, y que desde lo alto de su grandeza considere con desdén al rebaño de mujeres que se atreven a hablarle en pie de igualdad". De Beauvoir, El segundo sexo, 22.
} 


\section{enn-claves}

por ello en arbitraria o simplemente idiosincrásica". ${ }^{46}$ Lo que a Arendt le importa resaltar en su lectura de Sócrates, cree Villa, es que para Sócrates (a diferencia de Platón) no hay oposición entre verdad y opinión, aunque la afinidad tiene que revelarse a través del diálogo. ${ }^{47}$

El otro componente de la vida política descrito por Arendt como "la otra cara de la acción" es el pensamiento que se expresa mediante la palabra y el discurso y que tampoco debe separarse de la experiencia. Contraria a los conocimientos científicos, que son unidireccionales en su interpretación de los hechos, la comprensión es un proceso interminable que inicia con la vida y concluye con la muerte. Es el medio de reconstrucción del sentido común que puede resolver las contradicciones del antagonismo que brota ante las exigencias de igualdad y respeto hacia los cuerpos y emociones de las mujeres, sin sustraerse a la exigencia de comprender el mundo incluyendo su inédita perspectiva. Mientras tanto el desierto continúa extendiéndose y su peligro acecha en la resistencia a integrar a las mujeres en la cultura y con ello el significado de sus experiencias.

Hoy el desierto del totalitarismo anquilosado se revela en la actitud de jóvenes feministas que, a pesar de haber crecido inmersas en el discurso moderno de los derechos humanos, tienen que enfrentar un mundo patriarcal más violento que el que enfrentaron sus madres; pero también en la soez expresión de jóvenes varones cuya frustración crece al no poder realizar la función de dominio que el patriarcado en que crecieron les había prometido. La imagen que proyecta el mal radical del siglo XXI son jóvenes mujeres que reaccionan ante el agravio de la violencia recrudecida y el feminicidio ostensivo; y varones - jóvenes y viejos - que consideran un agravio la limitación de sus privilegios en el ejercicio de la violencia contra los cuerpos de ellas. En todos los casos que hemos analizado es evidente que la ambigüedad propia de las relaciones humanas no justifica la imposición ni la violencia. Más bien obliga a esmerar el cuidado en el trato entre las personas.

Acercarnos al análisis crítico del desierto actual (la condición antipolítica del presente) bajo la luz de la filosofía arendtiana permite desarrollar nuevas maneras de pensar la realidad humana, que no se desvinculen del cuerpo ni de la sensibilidad. La pasión por

\footnotetext{
${ }^{46}$ Dana R. Villa, “Arendt y Sócrates", en VV. AA., Hannah Arendt, el legado de una mirada (Madrid: Sequitur, 2008), 120.

47 Según Dana Villa "no solemos tener consciencia de nuestra propia doxa, de nuestra propia perspectiva sobre el mundo que compartimos. La doxa necesita ser trabajada, arrancada de nuestras entrañas del modo doloroso que denota el símil de la comadrona". Ibid., 120-121.
} 


\section{enn-claves}

comprender la existencia humana desde la experiencia ilumina la relación que existe entre el nivel intelectual del juicio y la potencia de transformación que tiene la acción. Y si, como asegura la filósofa, el ser humano es un ser de inicio y de infinita creatividad, el único ser capacitado para superar el desierto es él mismo. ${ }^{48}$ La capacidad de juzgar se activa precisamente en el momento de tomar decisiones — en eso consiste la capacidad de realizar milagros - porque comprender y actuar no deben oponerse, como ocurre en la historia del totalitarismo cuando por diversas circunstancias los seres humanos se excusaron de pensar.

La renuncia a pensar, como sabemos, implica la imposibilidad de comprender y de ahí deriva justamente la pérdida del sentido común, que es la única forma de preservar una convivencia efectiva que permita la coexistencia entre los seres humanos en general y, particularmente, entre las mujeres y los varones. Corresponde pues a quienes han resistido las tormentas de arena comenzar a innovar y a desplegar las posibilidades de futuro, sin olvidarse de los riesgos siempre presentes, ya que, como dice Hannah Arendt,

La psicología - la disciplina de ajustar la vida humana al desierto - y los movimientos totalitarios - las tempestades de arena, en las cuales lo que es tranquilo como la muerte explota repentinamente en pseudo-acción- plantean un peligro inminente a las dos facultades humanas que pacientemente nos capacitan para transformar el desierto en lugar de transformarnos a nosotros mismos: las facultades conjuntadas de acción y pasión. ${ }^{49}$

Finalmente, como dijera la más reconocida filósofa política del siglo XX, sólo la realización sintética de un corazón inteligente y una inteligencia sensible o sintiente puede permitir comprender, desde el horror de la violencia y la desigualdad, el mundo complejo en que vivimos y las posibilidades de resolución que aún tenemos. No debemos olvidar que, aún en el extendido desierto del siglo XXI, todavía existen los oasis.

\section{Bibliografía}

Arendt, Hannah. Los orígenes del totalitarismo, Volumen. I. México: Planeta Agostini, 1994.

\footnotetext{
48 "Es el propio ser humano quien, de un modo maravilloso y misterioso, está dotado para hacer milagros. [Y] este don es lo que en el habla habitual llamamos la acción”. Hannah Arendt, ¿Qué es la política? (Barcelona, Paidós, 1997), 64-65.

49 Arendt, "Del desierto".
} 


\section{enn-claves}

Arendt, Hannah. De la historia a la acción. Barcelona: Paidós, 1995.

Arendt, Hannah. ¿Qué es la política? Barcelona: Paidós, 1997.

Arendt, Hannah. Los orígenes del totalitarismo, Madrid: Taurus, 1998.

Arendt, Hannah. Sobre la violencia. Madrid: Alianza, 2005.

Arendt, Hannah. "Del desierto y los oasis". La nación, 19 de noviembre, 2006.

https://www.lanacion.com.ar/cultura/del-desierto-y-los-oasis-nid859761.

Bocchetti, Alessandra. Lo que quiere una mujer. Barcelona: Cátedra, 1996.

Cacho, Lydia. Los demonios del edén. México: Grijalbo, 2006.

Cruz, sor Juana Inés de la. "Redondillas”. En Obras completas. México: Miguel Ángel Porrúa, 1996.

De Beauvoir, Simone. El segundo sexo. 1949.

De Beauvoir, Simone. El existencialismo y la sabiduría de los pueblos. Barcelona: Edhasa, 2006.

Frye, Marilyn. Politics of Reality: Essays in Feminist Theory. Trumansburg, NY: Crossing Press, 1983

Kohan, Alexandra, "Acostarse con un boludo no es violencia". Entrevista de Agustina Escobar. Panamá. No todo es política, 6 de junio del 2019. http://www.panamarevista.com/acostarse-con-un-boludo-no-es-violencia/.

López, Magdalena. "Por una pedagogía del cuidado, el acuerdo y la responsabilidad afectiva". LATFEM Periodismo Feminista, 8 de junio de 2019. https://latfem.org/por-una-pedagogia-del-cuidado-el-acuerdo-y-la-responsabilidadafectiva/?fbclid=IwAR2hEKPwR41tn03TzeUk5_SSnqtdZKdulGEdK4fOydfXwSFEeYW4W6sBUs.

Segato, Rita. Las estructuras elementales de la violencia. Buenos Aires: Universidad Nacional de Quilmes, 2003.

Villa, Dana R. “Arendt y Sócrates”. En VV. AA. Hannah Arendt, el legado de una mirada, 120-121. Madrid: Sequitur, 2008.

Weil, Simone. A la espera de Dios. Madrid: Trotta, 1993.

Weil, Simone. Pensamientos desordenados. Madrid: Trotta, 1995. 